\title{
Unusual visual loss after snakebite
}

Tungpakorn N (1)

(1) Department of Ophthalmology, Sawanpracharak Hospital, Nakhonsawan, Thailand.

\begin{abstract}
Snakebites are endemic in some parts of Thailand, being associated with several complications. Ocular disturbances are uncommon, except in cases of corneal or conjunctival injury, when the eye is directly exposed to the snake venom. The present study presents a case of combined ophthalmic artery occlusion and transient central retinal artery occlusion with macular ischemia after a Russell's viper bite.
\end{abstract}

Key words: snakebite, central retinal artery occlusion, macular ischemia, Vipera russelli siamensis.

\section{INTRODUCTION}

Snakebites are a common medical emergency in the tropics, particularly in rural and farming areas. Venomous snakebites may result in neurologic or hemostatic dysfunction, and cause multisystemic involvement. Viperidae venoms act mainly on blood and blood vessels. Reports of ophthalmic manifestations after viperine snakebites include subconjunctival hemorrhage, hyphema, retinal hemorrhage, vitreous hemorrhage, central retinal artery occlusion, visual loss due to cortical infarction, and macular infarction (1-5).

Ophthalmic artery occlusion, retinal necrosis, and macular infarction associated with snakebites are infrequent ocular effects, and to the best of our knowledge only one case has been reported in the literature (5). This paper reports the development of secondary ophthalmic artery occlusion and transient central retinal artery occlusion with macular ischemia after viper envenomation in a single case study.

\section{CASE REPORT}

A 32-year-old Thai man was bitten by a snake on his right foot while working in a sugarcane field. The snake (Russell's viper, subspecies Vipera russelli siamensis) threatened, bit and escaped but the species was confirmed by the patient and witnesses. He slowly lost consciousness for three hours after the bite. He was admitted to a local general hospital in an unconscious state and received first aid, including prompt medical treatment and supportive care. Russell's viper antisnake venom (ASV) was given due to prolonged venous clotting time (VCT $>30$ minutes). He was transferred immediately to the medical intensive care unit at the Sawanpracharak Hospital, Nakhonsawan, Thailand.

At the time of admission, he was drowsy, with a Glasgow Coma Score (GCS) of $9\left(\mathrm{E}_{2} \mathrm{~V}_{2} \mathrm{M}_{5}\right)$, his pulse was 120 beats per minute, blood pressure 110/60 $\mathrm{mmHg}$, and presented normal respirations. Fang marks were visible on the right foot with a minimal localized swelling. Bleeding 
from the bite site was observed. Blood laboratory tests revealed normal hemoglobin level $(13.0 \mathrm{~g} /$ $\mathrm{dL})$, normal platelet count $(137,000$ cells $/ \mu \mathrm{L})$, decreased fibrinogen $(143 \mathrm{mg} / \mathrm{dL}$; normal = 248-328 $\mathrm{mg} / \mathrm{dL}$ ), prolonged prothrombin time ( $>200$ seconds; normal $=12.0-16.5$ seconds) and prolonged partial prothrombin time $(>200$ seconds; normal $=25.0-40.0$ seconds $)$ while VCT returned to 18 minutes. Results of renal function tests, electrocardiography, and computed tomography of the brain were normal.

The patient regained consciousness 18 hours after the snakebite. Five hours later, he noticed and started complaining of diminished vision in his left eye. He sought an ophthalmology consultation a couple of days after the snakebite due to a rapid painless visual loss in his left eye. His best corrected visual acuity (BCVA) was recorded as $6 / 6$ in the right eye (OD) and no light perception in the left eye (OS). The intraocular pressures were $12 \mathrm{mmHg} \mathrm{OD}$ and $10 \mathrm{mmHg}$ OS. Ocular examination disclosed unremarkable anterior segment in both his eyes. Relative afferent pupillary defect was observed in the left eye. Fundus examination revealed diffuse whitening and swollen mark of the entire retina and choroid, possibly by decreasing mark of both retinal and choroidal perfusion. By increasing contrast to the white background, the left optic disc color and macula appeared more reddish (Figure 1). Unfortunately, there was no fluorescein angiography reported due to lack of information regarding the status of choroidal circulation during the first visit.
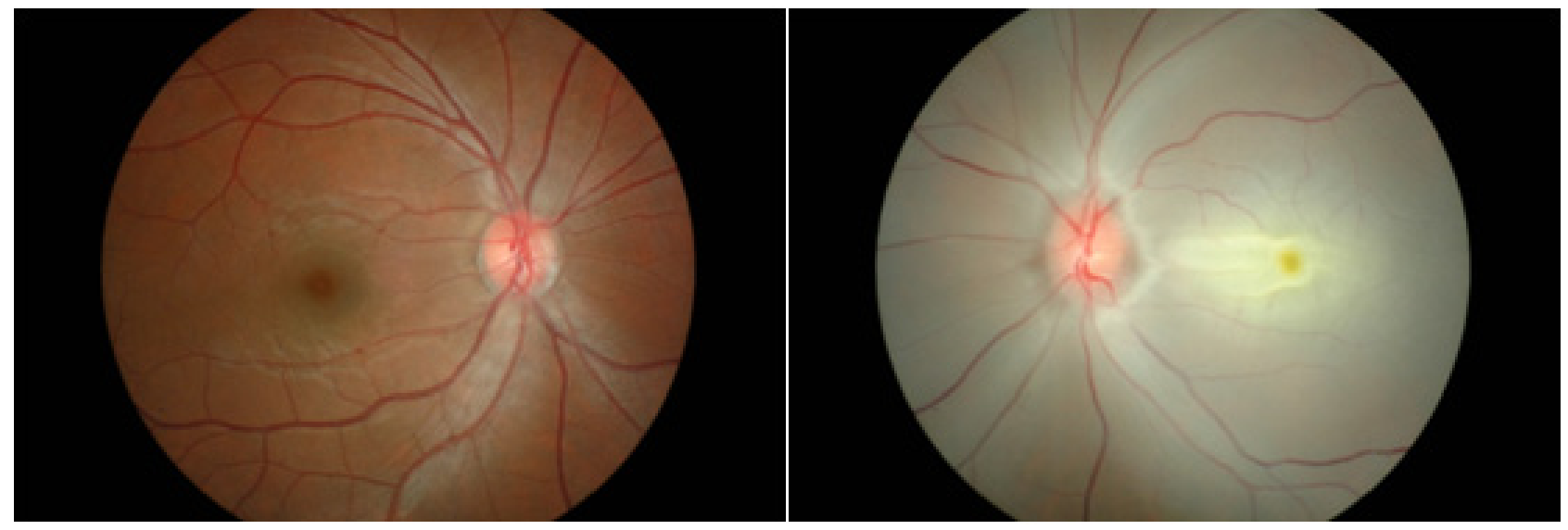

Figure 1. Fundus photograph showing marked whitish retina and a cherry-red spot at the macula of the left eye.
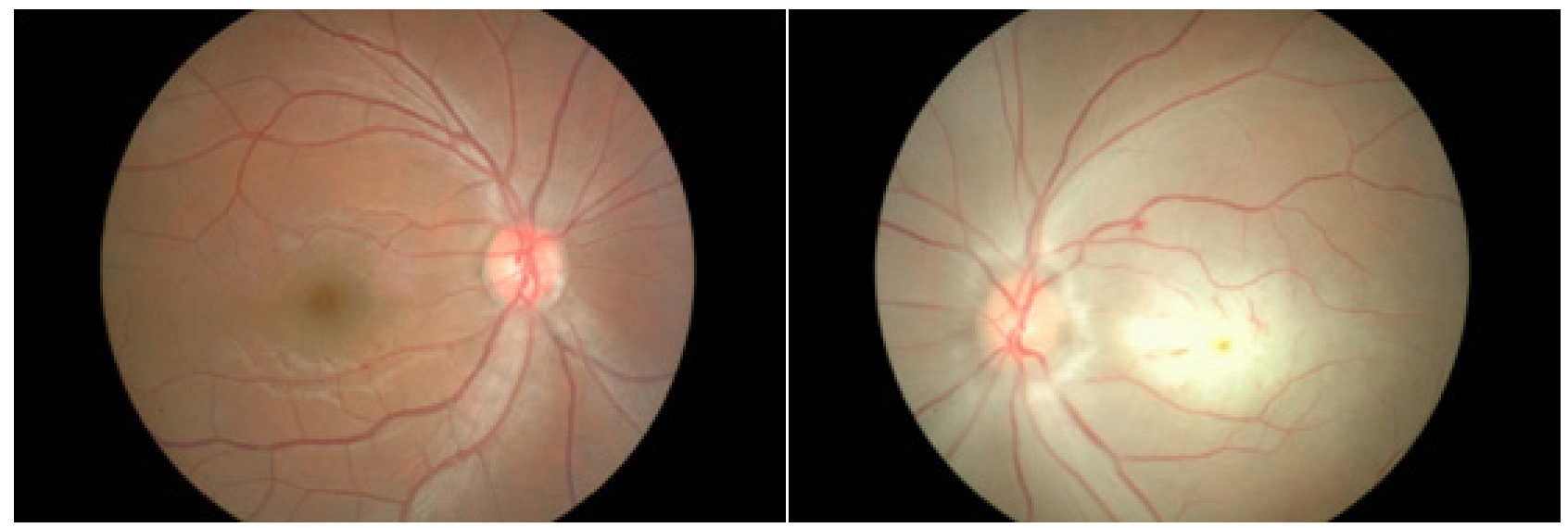

Figure 2. Fundus photograph showing the outer retinal ischemia minimally subsided, as seen by decreased swelling and reddish fundus, and still perifoveal whitening of the inner retina in the left eye. 


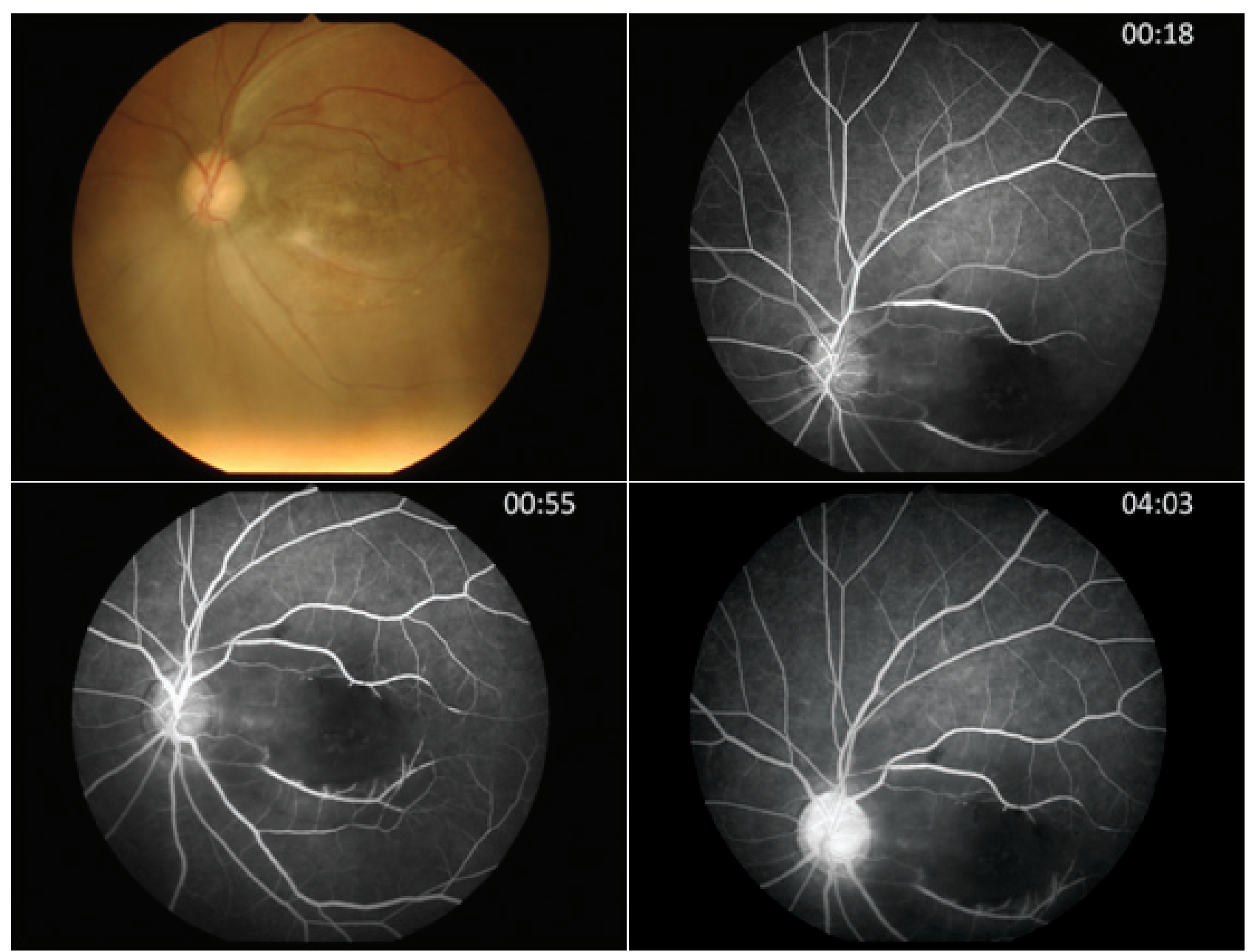

Figure 3. Fundus photograph and fluorescein angiography of the left eye showed resolutions of retinal whitening, generalized attenuation of retinal vessels especially inferotemporal branch, and atrophic macula with clumping pigment. Optic disc appeared slightly pale and atrophic.

Two weeks later, the choroidal background appeared more reddish than previously observed and the fundus picture presented more whitening of the macula which may be interpreted by the increased contrast by reperfusion of the choroidal system. Also, the macula became more swollen, confirmed by $+78 \mathrm{D}$ contact lens examination (Figure 2).

Six weeks after the incident, fundoscopic examination in the left eye showed large cupping, atrophic and pale optic disc. All the major retinal arterioles showed attenuation, especially on the inferotemporal branch, which were confirmed by the angiogram. There were some coarse granular changes of the pigmented background. The foveal avascular zone was enlarged and all the arterioles around it ended abruptly (Figure 3). Ocular treatment was ineffective since the patient was not responsive to standard treatments. In addition, the visual prognosis was extremely poor in his left eye.

\section{DISCUSSION}

Snake venom is a complex mixture of several enzymes and proteins, toxic polypeptides, and inorganic components. It contains numerous toxins, and their combined action has a more potent effect than that of their individual effects. In general, venoms are described as either neurotoxic or hematotoxic. Systemic manifestations of snakebites depend on specific toxins that constitute the venom. Also, Viperidae snake venom is comprised of mixed enzymes and toxins with rich components dominantly affecting hemostatic mechanisms, some of which appear to have opposing effects (6). While there are enzymes that cause hypofibrinogenemia, hypoprothrombinemia, thrombocytopenia and fibrinolysis; at the same time, there are potent proteases (e.g. arginine esterase and hydrolase) acting as activators of 
coagulation factors $\mathrm{X}$ and $\mathrm{V}$, thereby promoting coagulation (7). In addition, enzymes - such as hyaluronidase - damage connective tissues, leading to enhanced toxin dissemination. The net effect of these enzymes is activation of the intrinsic coagulation pathway, leading to the formation of numerous microthrombi in the circulation and, therefore, consumption of coagulation factors and platelets $(8,9)$. The end result is usually internal and external bleeding due to disseminated intravascular coagulation (DIC) that may cause massive intravascular coagulation with consequent ischemic sequel to major organs (10). Toxic vasculitis caused by certain viperine species may result in thrombosis or indicate direct action of the venom on vascular endothelial cells $(11,12)$.

Lastly, hemorrhagins-complement-mediated toxic components of Viperidae snake venom may provoke severe vascular spasm, endothelial damage, and increased vascular permeability, all of which might contribute to vascular occlusion $(11,12)$. Moreover, hyperviscosity caused by hypovolemia and hypoperfusion secondary to hypotension may also contribute to vessel occlusion. Any inherent deficiency of protein C, protein S, and antithrombin III may manifest too (13).

Various mechanisms that have been proposed as causative of rare complication after snake bite in this case are summarized below:

- Disseminated intravascular coagulopathy induced by the viper toxins may cause vessel-occlusive thrombi (especially with an underlying procoagulant state), which can account for the thrombi in the ophthalmic artery (11).

- Variations in viper venom composition, in terms of its hemorrhagic, anticoagulant, and other activities, may favor thrombosis, as opposed to bleeding (14).

- Snake venom hemorrhagins could be responsible for inducing vasculitis, which leads to vasospasm, endothelial damage and increased vascular permeability (12).

- A preexisting procoagulant state, due to a mutation in factor $\mathrm{V}$, deficiencies of protein $\mathrm{C}$ or $\mathrm{S}$ or anti-thrombin III, and antiphospholipid antibodies, may result in a tendency toward thrombosis in large vessels $(7,13)$.
- Finally, the direct action of the venom toxins or fibrin emboli into the ophthalmic artery which later result in retinal arteriolar ischemia and choroidal ischemia (12).

Ocular complications resulting from snakebite are not commonly reported in the literature. However, subconjunctival hemorrhage, hyphema, retinal and vitreous hemorrhages are well-known effects of viper envenomation. Other rare problems described included ptosis, ophthalmoplegia, keratomalacia, uveitis, central retinal artery occlusion, unilateral or bilateral optic neuritis, visual loss due to cortical infarction, and macular infarction (3-5, 15).

In conclusion, the patient had an ophthalmic artery occlusion and transient central retinal occlusion with secondary macular infarction after the snakebite. Although it is rare, it can become very severe and lead to vision-threatening situations. However, the actual cause of this case has not been reported or literately confirmed.

\section{ACKNOWLEDGEMENTS}

Special thanks for all physicians at Sawanpracharak Hospital, Nakhonsawan, who participated in treating this patient.

\section{COPYRIGHT}

(C) CEVAP 2010

\section{SUBMISSION STATUS}

Received: January 13, 2010.

Accepted: May 19, 2010.

Abstract published online: June 7, 2010.

Full paper published online: August 31, 2010.

\section{CONFLICTS OF INTEREST}

There is no conflict.

\section{CORRESPONDENCE TO}

NARONG TUNGPAKORN, Department of Ophthalmology, Sawanpracharak Hospital, Nakhonsawan, Thailand, 60000. Phone: +66 0 5621 9888. Fax:+66 05621 9899. Email: mootpk@ yahoo.com.

\section{REFERENCES}

1. Kweon EY, Lee DW, Ahn M, Nork TM, Cho NC. Vision loss following snakebite in a patient with controlled aplastic anemia. J Venom Anim Toxins incl Trop Dis. 2009;15(1):163-7. 
2. Rao BM. A case of bilateral vitreous haemorrhage following snake bite. Indian J Ophthalmol. 1977;25(2):1-2.

3. Bhalla A, Jain AP, Banait S, Jajoo UN, Kalantri SP. Central retinal artery occlusion: an unusual complication of snakebite. J Venom Anim Toxins incl Trop Dis. 2004;10(3):311-4.

4. Merle H, Donnio A, Ayeboua L, Plumelle Y, Smadja D, Thomas L. Occipital infarction revealed by quadranopsia following snakebite by Bothrops lanceolatus. Am J Trop Med Hyg. 2005;73(3):583-5.

5. Singh J, Singh P, Singh R, Vig VK. Macular infarction following viperine snake bite. Arch Ophthalmol. 2007;125(10):1430-1.

6. Marsh NA. Snake venoms affecting the haemostatic mechanism: a consideration of their mechanisms, practical applications and biological significance. Blood Coagul Fibrinolysis. 1994;5(3):399-410.

7. Siigur J, Aaspollu A, Tonismagi K, Trummal K, Samel M, Vija H, et al. Proteases from Vipera lebetina venom affecting coagulation and fibrinolysis. Haemostasis. 2001;31(3-6):123-32.

8. Bhargava RK, Hakim A, Shah PK, Mathur SB, Ujjwal JS. Disseminated intravascular coagulation in cases of snake bite (Echis carinatus). J Assoc Physicians India. 1976;24(10):671-75.

9. Than-Than, Hutton RA, Myint-Lwin, Khin-EiHan, Soe-Soe, Tin-Nun-Swe, et al. Haemostatic disturbances in patients bitten by Russell's viper (Vipera russelli siamensis) in Burma. Br J Haematol. 1988;69(4):513-20.

10. Schwartzman RJ, Hill JB. Neurologic complications of disseminated intravascular coagulation. Neurology. 1982;32(8):791-7.

11. Murthy JM, Kishore LT, Naidu KS. Cerebral infarction after envenomation by viper. J Comput Assist Tomogr. 1997;21(1):35-7.

12. Bashir $\mathrm{R}$, Jinkins J. Cerebral infarction in a young female following snake bite. Stroke. 1985;16(2):328-30.

13. Kumar V, Cortan RS, Robbins SL. Basic pathology. $5^{\text {th }}$ ed. Bangalore: Prism books PVT; 1992. p. 6970 .

14. Hayreh SS. Transient central retinal artery occlusion following viperine snake bite. Arch Ophthalmol. 2008;126(6):870-1.

15. Sanghavi NG, Amin SK, Naik RS. Bilateral optic neuritis following snakebite - a case report. J Assoc Physicians India. 1982;30(2):117-8. 